\section{NANOSTRUCTURED MATERIALS DEVELOPMENT FOR SPACE POWER}

\author{
R.P. Raffaelle, B.J. Landi, J.B. Elich, and T. \\ Gennett \\ Rochester Institute of Technology \\ Rochester, NY
}

\section{S.L. Castro}

Ohio Aerospace Institute, Brookpark, $\mathrm{OH}$

S.G. Bailey and A.F. Hepp

NASA Glenn Research Center Cleveland, $\mathrm{OH}$

\begin{abstract}
There have been many recent advances in the use of nanostructured materials for space power applications. In particular, the use of high purity single wall nanotubes holds promise for a variety of generation and storage devices including: thin film lithium ion batteries, microelectronic proton exchange membrane (PEM) fuel cells, polymeric thin film solar cells, and thermionic power supplies is presented. Semiconducting quantum dots alone and in conjunction with carbon nanotubes are also being investigated for possible use in high efficiency photovoltaic solar cells. This paper will review some of the work being done at RIT in conjunction with the NASA Glenn Research Center to utilize nanomaterials in space power devices.
\end{abstract}

\section{INTRODUCTION}

There has always been a strong interest in the space power community for high specific power conversion and storage devices. Increasing the efficiency of these devices without incurring any additional mass penalty can provide tremendous cost benefits to both missions and spacecraft. Often, improvements in the power system can be mission enabling as electrical storage mass alone accounts for about $10 \%$ of all spacecraft mass. There is currently much interest in the use of nanotechnology in the realm of space power. With the recent developments in the synthesis of single wall carbon nanotubes and semiconducting quantum dot systems, the use of nanomaterials in the development of the nextgeneration of space power supplies is emerging. The inherent control over the materials properties offered by quantum confinement and the enhancement in catalytic surface area offered by the extremely high aspect ratio nanotubes are primed for exploration in power devices.

\section{LITHIUM ION BATTERIES}

Since their inception by Sony in 1991, lithium ion batteries have steadily been replacing $\mathrm{Ni}$ $\mathrm{Cd}$ as the chemistry of choice. They have almost three times the specific energy, long cycle lives $(>1000)$, and low self-discharge. 'The current limitation in use of $\mathrm{Li}$ ion batteries for a variety of space power applications (remote sensing, communcation, etc.) is in their inability to support high discharge and charge rates. This stems from the low Li-ion solid state diffusion of the electrode materials. ${ }^{2}$ Much progress has been made recently using a variety of different nanoscale anode materials. $^{3}$ In particular, the use of single wall carbon nanotubes in lithium battery anodes appears to have outstanding potentional. ${ }^{4}$

\section{Carbon Nanotube Anodes}

Carbon based materials have been the material of choice for lithium storage in $\mathrm{Li}$-ion batteries for some time. ${ }^{5-6}$ Now, with the more recent discovery of new crystalline forms of carbon such as single and multi-walled nanotubes it appears that this trend may well continue. ${ }^{7-9}$ This is due to the fact that, in contrast to carbon black, nanotubes offer a more accessible structure for $\mathrm{Li}$ interaction.

The accessibility of the graphene structure of a carbon nanotubes to lithium ion storage has been estimated to have a $\mathrm{Li}$ to $\mathrm{C}$ ratio greater than 1 to $3 .^{10}$ This equates to a potential lithium capacity per mass that greatly exceeds any currently utilized anode material. The anode surface area per battery volume provided by these nanotubes would also increase by several orders of magnitude. This increase should decrease the internal battery resistance and increase attainable charge and discharge rates of $\mathrm{Li}$ ion batteries. This could potentially have a dramatic effect on the use of these batteries in space power systems.

Figure 1 shows high purity single wall carbon nanotubes produced by laser vaporization. The synthesis and purification of the materials was performed using the procedure outlined by Dillon et. al. ${ }^{11}$ Figure 2 shows the cycling results for a polymer composite anode doped with the SWNTs. The anode consisted of 0.056 wt $\%$ SWNT's, 13.2 wt $\%$ polyacrylnitrile, $\quad 9.6$ wt \% lithium hexaflurophosphate, and $77.1 \%$ ethelyene carbonate cast onto a copper foil. The anode was cycled using an ordinary three-electrode cell and a $1 \mathrm{C}$ rate (assuming a capacity of $1000 \mathrm{mAhr} / \mathrm{g}$ ). The resulting capacity exceeded that of a $\mathrm{Li}$ to $\mathrm{C}$ ratio of greater than 1 to 3 for the 50 cycles measured at this relatively high $\mathrm{C}$ rate.

This is a preprint or reprint of a paper intended for presentation at a conference. Because changes may be made before formal publication, this is made available with the understanding that it will not be cited or reproduced without the permission of the author. 


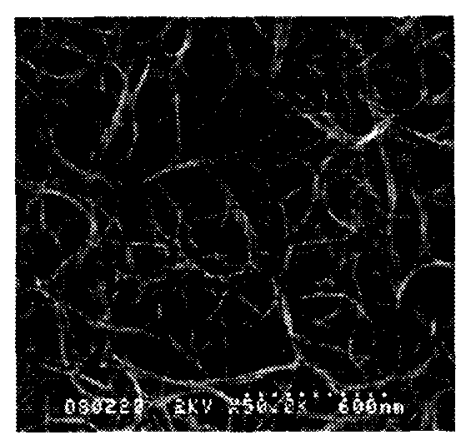

Figure 1. SEM micrograph of high purity single wall carbon nanotubes produced by laser vaporization.

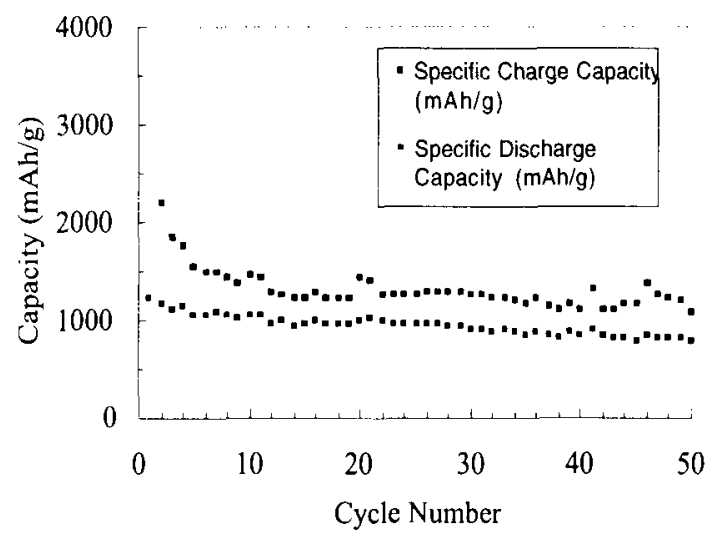

Figure 2. Specific Li capacity of a SWNT doped polymeric anode cycled at a $1 \mathrm{C}$ rate.

\section{PEM FUEL CELLS}

NASA has been utilizing fuel cells for spacecraft power since the early 60's. Early fuel cells relied on potassium chloride as their electrolyte. They approached efficiencies as high as $70 \%$, however, cost has rendered them obsolete. Other fuel cell types such as phosphoric acid, molten carbonate, or solid oxide fuel cells have the drawbacks of low specific power and the necessity of high temperature operation in order to function efficiently. Recently there has been considerable effort recently in the development of thin film, portable, microelectronic fuel cells for space applications. These cells use a thin polymeric proton exchange membrane (PEM) and primarily rely upon a direct hydrogen feed from stored gas or provided by an electrolyzer. An alternative version of a PEM fuel cell, the so-called direct methanol fuel cell (DMFC), uses a catalyst in the anode to extract hydrogen directly from a liquid methanol fuel source. ${ }^{12}$
In 1998, NASA Glenn Research Center teamed with Allied Signal to design and develop a $5.25 \mathrm{~kW}$ PEM fuel cell stack suitable for use with a Reusable Launch Vehicle (RLV). This partnership resulted in successfully demonstrating a $5.25 \mathrm{~kW}$ full-size PEM fuel cell stack. ${ }^{13}$ Currently researchers at the NASA Glenn Research Center, Jet Propulsion Lab, National Renewable Energy Lab, and elsewhere are investigating how single wall carbon nanotubes, either for hydrogen storage or as active anode and cathode materials, can be used to make efficient PEM fuel cells low-temperature power devices for space.

\section{Hydrogen Storage in Single Wall Carbon Nanotubes}

A current impediment in the use of PEM fuel cell for space application lies in the problem of how to store significant amounts of hydrogen without a tremendous mass penalty and allow operation of the cells at relatively low temperature (i.e., $<80^{\circ} \mathrm{C}$ ). Due to the size and mobility of hydrogen in most materials it must either be placed in thick wall containment vessel or chemically bound in a compound. The former has the problem of eliminating any high specific power and the latter normally requires high temperature $\left(>400{ }^{\circ} \mathrm{C}\right)$ to release the hydrogen. Recently it has been demonstrated that single wall carbon nanotubes (SWNT) may be the answer to this problem. ${ }^{14}$

Researchers at the National Renewable Energy Lab (NREL) have demonstrated a hydrogen storage capacity of $5-10 \mathrm{wt} \%$ at pressures less than 1 bar near room temperature in SWNT's. ${ }^{14}$ Such hydrogen storage capacity would be a significant advance for the use of hydrogen as a fuel when high gravimetric density of hydrogen is the figure of merit. $Y e$ et al. recently demonstrated that hydrogen absorption on ropes of single wall nanotubes can exceed $8 \mathrm{wt} \%{ }^{15}$ They found that the cohesive energy is strongly affected by the quality in crystalline order in the ropes. Hydrogen storage by SWNTs may well pave the way to autonomous regenerative PEM fuel cells for space.

\section{SWNT PEM Fuel Cell Anodes and Cathodes}

In addition to their utility in storing hydrogen, carbon nanotube may also pose much promise in producing more efficiency PEM fuel cell anode and cathodes. The incorporation of these highly electrically and thermally conductive materials into a polymeric based membrane could dramatically improve overall transport in the PEM devices. They can also be used to directly support the catalysts used 
in the electrodes. Li et. al. demonstrated that using SWNTs as a support for Pt in a DMFC cathode yielded better performance as compared to standard Vulcan XC-72 carbon doped with equivalent amounts of Pt. ${ }^{16}$ SWNT's have also been used to support $\mathrm{Pt}-\mathrm{WO}_{3}$ and $\mathrm{Pt}-\mathrm{Ru}$ for use as anodes in DMFC's. The higher electrochemical surface area offered by the use of nanotubes increased the electrochemical reactivity and also improved the stability with $\mathrm{N}_{2}$ content. $^{17}$ Figure 3 shows the percent power increase measured using SWNTs in place of ordinary graphite in a Viatronix, Inc. prototype micro fuel cell.

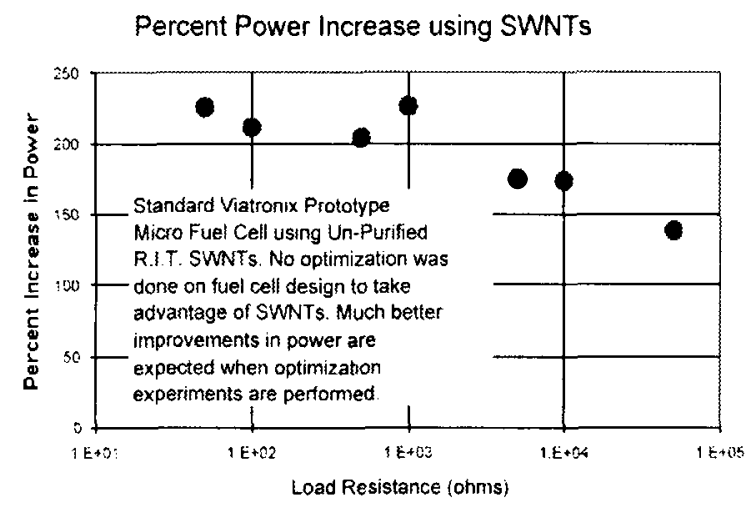

Figure 3. Percent power increase versus load resistance using single wall carbon nantoubes in the Viatronix micro fuel cell. (Measurement courtesy of Phillip LaMarre, Viatronix, Inc.)

\section{QUANTUM DOT SOLAR CELLS}

The space photovoltaic community is well aware of the cost benefits to both mission and spacecraft development associated with the continued increase in solar cell efficiency. The developmental efforts in regards to both $\mathrm{Si}$ and GaAs based cells have resulted in nearly eliminating the efficiency differences between actual devices and theoretical estimates. Over the past decade much of the cell efficiency improvements have resulted from the move towards multi-junction devices. However, as researchers continue to push the envelope they are looking towards new approaches, such as the use of nanostructured materials, in improving device efficiencies. $^{18}$

Theoretical results of Luque and Marti have shown that a photovoltaic device with an intermediate band of states resulting from the introduction of quantum dots can exceed the Shockley and Queisser model efficiency of a single junction. In fact, the efficiency of this type of a quantum dot device has a higher theoretical efficiency than a tandem cell device. ${ }^{19}$ A quantum dot is a nanocrystallite of semiconducting material that will behave essentially as a quantum mechanical 3-dimensional potential well for electrons. Luque and Marti calculated a theoretical efficiency of $63 \%$ for a device which included an ordered array of these dots within the intrinsic region of a $\mathrm{p}-\mathrm{i}-\mathrm{n}$ solar cell. Quantum dots have already been used successfully to improve the performance of other devices such as lasers, light emitting diodes, and photodetectors.

The efficiency increases offered by a quantum dot solar cell are due to the discrete states that result from the inclusion of the dots which will allow for absorption of sub-bandgap energies. The resulting current that can be extracted from the carriers in the dots is limited by the host material bandgap and not the individual photon energies.

The energy states of a quantum dot are inversely proportional to its size. The ground state absorption energy of a quantum dot is determined by

$$
\hbar \omega=E_{g}+\frac{\hbar^{2}}{2 m_{e}^{*} r^{2}} \pi^{2},
$$

where $E_{\mathrm{g}}$ is the bulk semiconductor bandgap, $h$ is planck's constant, $m_{\mathrm{e}}{ }^{*}$ is the electron effective mass, and $r$ is the quantum dot radius. If quantum dots are placed into an ordered array, the wavefunctions associated with the discrete electronic states of the quantum dots will overlap creating "mini-bands."

In an intermediate band solar cell, these minibands need to located energetically within the bandgap of the host semiconductor in such a way to optimize optical absorption. Roughly speaking, the bottom of the lowest mini-band energy level should be roughly $1 / 3$ of the bandgap energy of host above its valence band. ${ }^{20}$

Thin film polymeric solar cells may also benefit from the introduction of quantum dots. Solar cell which utilize conjugated polymers such as poly3-octyl-thiophene (P3OT) or poly-3-hexyl-thiophene (P3HT) making junctions with indium tin oxide (ITO) have suffered from low conversion efficiencies due to low transport mobility of the photogenerated carriers. The light that is absorbed in the conjugated polymers creates excitons or bound electron - hole pairs. Before these charges can contribute to any photocurrent they must first be separated. It has been shown that semiconducting quantum dots introduced into the polymeric matrix will serve as disassociation centers and improve overall device efficiency. ${ }^{21}$ However, even with the disassociation of the carriers their mobility in these materials is still quite low. This can be addressed to a certain extent by the use of nanorods instead of the spheroidal quantum dot counterparts. ${ }^{22}$ 
The problem of low carrier mobility in thin film polymeric solar cells may be addressed through the use of SWNTs. It has been demonstrated that even a small weight percent doping of SWNTs in a polymeric thin film can dramatically improve its electrical conductivity. ${ }^{23}$ In addition, SWNTs can themselves be semiconducting and are very good absorbers in the visible range. The may also serve a similar role as that of the quantum dots when introduced into these polymers. It has been measured that the open circuit voltage of P3OT/ITO devices will improve with the introduction of SWNTs. ${ }^{24} \mathrm{~A}$ doubling in percent external quantum efficiency in a multi-wall nanotube/PPV device as compared to an ITO/PPV device was observed. Photoluminescence data reflects a proposed energy transfer from PPV to nanotubes, attributed to hole collection at the nanotube electrode. ${ }^{25}$

Future thin film polymeric devices may well utilize combinations of both quantum dots and carbon nanotubes within the same device. There is much current activity in the coordination of quantum dot to carbon nanotubes. Through functionalization it is possible to directly attach the dots to either the tube ends or to their side walls. ${ }^{26}$ Optical absorption spectroscopy has demonstrated effective charge transfer from CdSe nanocrystals to the SWNTs to which they were attached. ${ }^{27}$ Using these materials in consort may well provide an entirely new type of photovoltaic device for the future.

The NASA Glenn Research Center in collaboration with RIT has been investigating different methods of producing quantum dots that would be suitable candidates for a quantum dot photovoltaic solar cell and thin film cells utilizing both quantum dots and SWNTs. This is prompted not only by the fact that by improving device efficiency we can increase the specific power of space solar arrays but also by the fact that quantum dots and SWNTs may also have some definite thermal and radiation hardness advantages as well. ${ }^{28}$

\section{Quantum Dot Chemical Bath Synthesis}

Colloidal methods of quantum dot synthesis such as reactions employing organometallic precursors or inverse micelles result in colloidal suspensions of nanoparticles in an organic solvent matrix. The nanoparticles are protected from interaction with each other by adsorption of a layer of organic molecules on the crystal surface; the chemical properties of the organic layer also serve to tune the solubility of the nanoparticles and can be altered to meet the desired properties.

While there is great interest in using nanocrystalline semiconductors, there are few established methods of synthesizing useful quantities of these compounds. The exception to this statement is the II-VI class of semiconductors such as CdS and CdSe. Only a few reports have been made about the synthesis of the ternary materials $\mathrm{CuInS}_{2}$ and $\mathrm{CuInSe}_{2}$ with very small particle size. With respect to their use in quantum dot solar cells and exciton dissociation, the size of the nanoparticle is a key factor. In practice however, synthesis of a desired size nanoparticle is not always simple. This is especially for the higher-order ternary and tertiary materials. When separate sources are used for the different metals and chalcogenides, binary materials are often preferentially formed as a result of the different solubilities of the products and reactivity of the precursors.

One method to circumvent the undesirable reaction products is through the use of single-source precursors. Single-source precursors are small molecules which include all the elements required in the final material. These precursors can be designed with many properties in mind including stoichiometry, solubility, and volatility.

As $\mathrm{CuInS}_{2}$ and $\mathrm{CuInSe}_{2}$ are promising materials for thin-film photovoltaics and quantum dot solar cells, our group has studied the formation of potential precursors to these materials and their subsequent conversion to the semiconducting materials. The molecular precursor $\left(\mathrm{PPh}_{3}\right)_{2} \mathrm{CuIn}(\mathrm{SEt})_{4}$ was first described by Hirpo et. al. in $1993 .{ }^{29}$ This charge-neutral molecule is made up of a copper(I) ion bound by two triphenylphosphine ligands, an indium(III) ion with two terminal ethanethiolate ligands, and two bridging ethanethiolate ligands which coordinate in a $\mu_{2}$ fashion between the metal centers. This molecule was found to decompose to $\mathrm{CuInS}_{2}$ below $260{ }^{\circ} \mathrm{C}$. Figure 4 shows the powder $\mathrm{x}$-ray diffraction pattern of $\mathrm{CuInS}_{2}$ nanoparticles formed at $300 \mathrm{C}$. The peaks exhibit significant broadening, characteristic of very small particles.

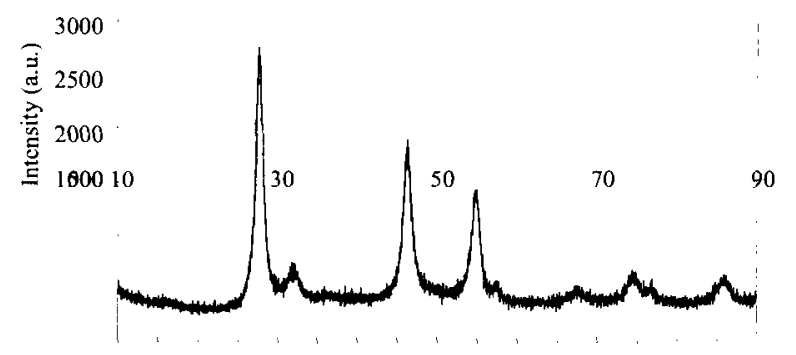

Figure 4. XRD pattern of $\mathrm{CuInS}_{2}$ nanoparticles. 
The quantum dots that are being produced at the NASA Glenn Research Center are being used to produce solar cells by inserting them into polycrystalline cell structure by combining nanoparticle solution deposition with MOCVD of the surrounding material. Colloidal dots with a low size distribution will self-assemble into ordered closepacked layers under conditions of slow evaporation of solvent. $^{30}$ The researchers at NASA are working in collaboration with the Wronski group at Penn State U. to deposit layers of suitable nanoparticles in amorphous Si p-i-n structure.

Photovoltaic devices have been constructed using P3OT doped with SWNTs produced by laser vaporization at RIT. The composite solution $(<1 \%$ $\mathrm{w} / \mathrm{w}$ ) was applied between aluminum and ITO coated glass substrates (see Figure 4). The SWNT-P3OT diode response produced a $\mathrm{V}_{\mathrm{oc}}$ in the range of 0.7-0.9 $V$, and the $I_{s c}$ was observed to double for the composite solar cells compared to those which contain P3OT without the SWNTs. Since the work functions for Al and ITO are reported as $4.3 \mathrm{eV}$ and $4.7 \mathrm{eV}$, respectively, the relatively higher $V_{o c}$ is proposed to be a result of a metal-insulator-metal (MIM) diode, corresponding to ITO-polymerSWNTs.

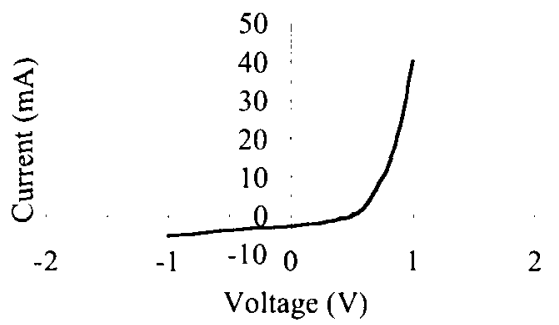

Figure 4. Current versus voltage response of a SWNT doped P3OT/ITO solar cell.

\section{THERMIONIC POWER SUPPLIES}

Thermionic power supplies are power supplies that convert heat directly into electrical energy. Unfortunately to produce efficient devices requires materials with extremely low work function, and to date, have required very high operating temperatures. The best devices produced to date have an efficiency of $15.1 \%$ using Mo electrodes operating at $1673 \mathrm{~K}$ with a $\Delta \mathrm{T}$ of $700 \mathrm{~K} .^{31}$

The use of such devices have been relegated primarily to deep space probes relying on nuclear fuel as their heat source. They have also been hampered due to the difficulty finding materials that will not undergo mechanical deformation or creep when operating at temperatures close to melting or their sublimation temperatures.
Recently it has been shown that small metal nanoscale particles $(10-100 \mathrm{~nm})$ or nanostructured thin films can be used to produce low work function materials. ${ }^{32}$ In addition, it has also been shown that SWNTs also have intrinsically low work functions which can be reduced via Cs doping. ${ }^{33}$ These materials may be used as stand-alone electrodes or as additives to other materials to produce thermionic power supplies.

The low work function of the carbon nanotubes have already found application in thin film field emission displays. ${ }^{34}$ The same types of polymer composites are currently being investigated by NASA for use in thermionic power generation. Ceramic-MWNT composites have recently been developed using a sol-gel technique which may allow for for higher temperature applications as well. ${ }^{35}$ Figure 5 shows a SWNT doped polymeric thin film material currently under investigation as a lowtemperature thermionic emitter.

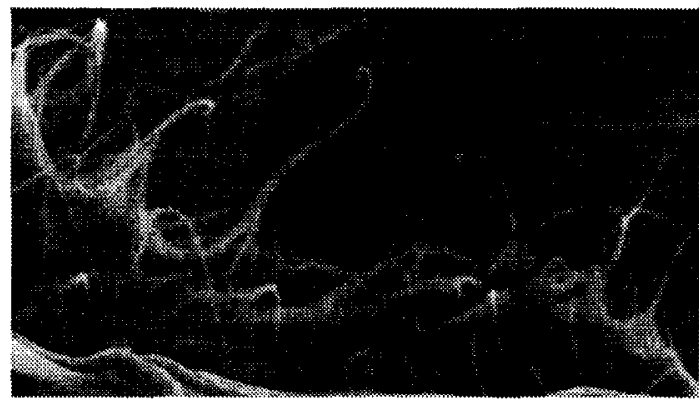

Figure 5. SEM micrograph of a SWNT doped thin film polymeric thermionic emitter.

\section{REFERENCES}

1. B.A. Johnson and R.E. White, J. of Power Sources 70 (1998) 48.

2. R. Moshtev and B. Johnson, J. of Power Sources $91(2000) 86$.

3. C.R. Sides, N. Li, C.J. Patrissi, B. Scrosati, C.R. Martin, MRS Bulletin, August (2002) 604.

4. R.P. Raffaelle, T. Gennett, J. Maranchi, P. Kumta, A.F. Hepp, M.J. Heben, A.C. Dillon, K.A. Jones, Proc. of 2001 Fall MRS Society Meeting, Making Functional Materials with Nanotubes, Vol. 706 (2001).

5. J.R. Dahn, T. Zheng, Y. Liu, and J.S. Xue, Science, 270, 590 (1995).

6. M.S. Dresselhaus and G. Dresselhaus, Adv. Phys. 30, 139 (1981).

7. J.M. Tarascon and M. Armand, Nature, 414, 359 (2001). 
8. A. Claye, J. Fischer, C. Huffman, A. Rinzler, and R.E. Smalley. J. Electrochem. Soc., 147, 2845 (2000).

9. P. Liu, G.L. Hornyak, A.C. Dillon, T. Gennett, M.J. Heben, and J.A. Turner, J. Electrochemical Soc.; Proceedings of the International Symposium, 31 (1999) 9.

10. J. Zhao, A. Buldum, J. Han, J.P. Lu, Phys. Rev. Lett. 85, 8 (2000) 1706.

11. Dillon reference

12. S.R. Narayahan, Aerospace Technology Innovation 10 (2002) 3.

13. M. Hoberect, NASA Aerospace Technology News 2 (2001) 6.

14. A.C. Dillon, K.M. Jones, T.A. Bekkedahl, C.H. Kiang, D.S. Bethune, M.J. Heben, Nature 386 (1997) 377.

15. Y. Ye, C.C. Ahn, C. Witham, B. Fultz, J. Liu, A.G. Rinzler, D.T. Colbert, K.A. Smith, R.E. Smalley, Appl. Phys, Lett. 74 (1999) 2307.

16. W. Li, C. Lian, J. Qui, W. Zhou, H. Han, Z. Wei, G. Sun, and Q. Xin, Carbon 40 (2002) 787.

17. B. Rajesh, V. Karthik, S. Karthikeyan, K. R. Thampi, J.-M. Bonard, B. Visiwanathan, Fuel 81 (2002) 2177.

18. A.J. Nozik, Annu. Rev. Phys. Chem. 52 (2001) 193.

19. A. Luque and A. Marti, Phys. Rev. Lett. 78 (1997) 5014.

20. R.P. Raffaelle, S.L. Castro, A.F. Hepp, S.G. Bailey, Prog. in Photovolt. 10 (2002) 1.

21. Arici, E.; Hoppe, H.; Reuning, A.; Sariciftci, N. S.; and Meissner, D. $17^{\text {th }}$ EPSE Conference Proc. 2001 .

22. Huynh, W. U.; Peng, X. and Alivisatos, A. P. Adv. Mater. 1999, 11, 923

23. B.J. Landi, R.P. Raffaelle, M.J. Heben, J.L. Alleman, W. VanDerveer, and T. Gennett, NanoLett. (2002) in press.

24. Kymakis, E.; Amaratunga, G. A. J. Appl. Phys. Lett. 80 (2002) 112.

25. Ago, H.; Petritsch, K.; Shaffer, M. S. P.; Windle, A. H.; Friend, R. H. Adv. Mat. 11 (1999), 1281.

26. Haremza, J. M.; Hahn, M. A.; Krauss, T. D.; Chen, S.; Calcines, J. Nano Lett. (2002), in press. 27. Banerjee, S.; Wong, S. S. Nano Lett. 2 (2000), 195.

28. B.G. Rax, C.I. Lee, A.H. Johnston, C.E. Barnes, IEEE Transactions of Nuclear Science 43 (1996) 3167.

29. Hirpo, W.; Dhingra, S.; Sutorik, A. C. and Kanatzidis, M. G. J. Am. Chem. Soc. 115 (1993) 1597.

30. C.B. Murray, C.R. Kagan, and M.G. Bawendi, Annu. Rev. Mater. Sci. 30 (2000) 545.
31. M. S. El-Genk, Y. Momozaki, Energy Conv. Manag., 43 (2002) 911.

32. C. W. Bates, Mater. Lett., 23 (1995) 1.

33. S. Suzuki, C. Bower, Y. Watanabe, O.Zhou, Appl. Phys. Lett., 76 (2000) 4007.

34. R. W. Sigel, Scripta Mater. 44 (2001) 2061.

35. P. Vincent, A. Brioude, C. Journet, S. Rabaste, S. T. Purcell, J. Le Brusq, J. C. Plenet, J. Non-Cryst. Solids 311 (2002) 130. 